\title{
Production of Biocellulosic Ethanol from Wheat Straw
}

\author{
Ismail, W. Ali ${ }^{1}$, Braim, R. Rasul ${ }^{1}$, Ketuly, K. Aziz ${ }^{2}$, \\ Awang Bujag, D. Siti Shamsiah ${ }^{2}$, Arifin, Zainudin ${ }^{2}$ \\ ${ }^{1}$ Salahaddin University, Science Education College, Chemistry Department, Erbil, Kurdistan Region, Iraq \\ ${ }^{2}$ Malaya University, Science Faculty, Chemistry Department, Malaysia
}

Correspondence to: wshyarali@yahoo.com, wshyarali@esc-ush.com (Ismail, W. Ali)

\begin{abstract}
Wheat straw is an abundant lignocellulosic feedstock in many parts of the world, and has been selected for producing ethanol in an economically feasible manner. It contains a mixture of sugars (hexoses and pentoses).

Two-stage acid hydrolysis was carried out with concentrates of perchloric acid, using wheat straw. The hydrolysate was concentrated by vacuum evaporation to increase the concentration of fermentable sugars, and was detoxified by over-liming to decrease the concentration of fermentation inhibitors. After two-stage acid hydrolysis, the sugars and the inhibitors were measured. The ethanol yields obtained from by converting hexoses and pentoses in the hydrolysate with the co-culture of Saccharomyces cerevisiae and Pichia stipites were higher than the ethanol yields produced with a monoculture of $S$. cerevisiae. Various conditions for hysdrolysis and fermentation were investigated. The ethanol concentration was $11.42 \mathrm{~g} / \mathrm{l}$ in $42 \mathrm{~h}$ of incubation, with a yield of $0.475 \mathrm{~g} / \mathrm{g}$, productivity of $0.272 \mathrm{~g} / \mathrm{l} \cdot \mathrm{h}$, and fermentation efficiency of $92.955 \%$, using a co-culture of Saccharomyces cerevisiae and Pichia stipites.
\end{abstract}

Keywords: wheat straw, two-stage acid hydrolysis, bioethanol, co-culture, fermentation.

\section{Introduction}

Lignocellulosic materials are renewable, largely unused, and abundantly available sources of raw materials for the production of ethanol fuel. A potential source for future low-cost ethanol production is to utilize lignocellulosic materials such as crop residues, grasses, sawdust, wood chips, oil palm empty fruit bunches, trunks, and fronds [1]. These materials contain sugars polymerized in the form of cellulose and hemicellulose, which can be liberated by hydrolysis and subsequently fermented to ethanol by microorganisms [2]. Hydrolysis can be performed with the use of enzymes or chemicals to further decompose the starch or cellulose to simple sugars [3]. The cellulose hydrolysis step is a major element in the total production cost of ethanol from lignocellulosic material [4]. Three groups of enzymes, i.e. endoglucanase, exo-glucanase and $\beta$-glucosidase, are involved in the cellulose-to-glucose process, with synergetic interactions [5]. Enzymatic hydrolysis or saccharification is mainly limited by a number of factors, including the crystallinity of the cellulose, the degree of polymerization, the moisture content, the available surface area, etc. [6]. Acid hydrolysis is becoming more popular, due to its lower cost and greater effectiveness than enzymatic hydrolysis [7]. The lignocellulosic material is subjected to strong concentrations of hydrochloric or sulfuric acid in order to begin the breakdown and separation of the materials [4].
Acid hydrolysis can be divided into two groups: (a) concentrated-acid hydrolysis and (b) dilute-acid hydrolysis. Concentrated-acid processes are generally reported to give a higher sugar yield (e.g. $90 \%$ of the theoretical glucose yield), and consequently a higher ethanol yield, than dilute-acid processes [3]. In addition, concentrated-acid processes can operate at low temperature, which is a clear advantage over dilute-acid processes [8]. There are other studies that apply hydrothermal processes [9], steam explosion [10], wet oxidation [11], alkaline peroxide [12] and ammonia fiber explosion [13] for biomass pretreatment in the ethanol process.

The sugars formed in the hydrolysate are fermented into ethanol. The most common microorganisms for this purpose are Saccharomyces cerevisiae and Zymomonas mobilis, which are not metabolized pentoses. However, almost one-third of the reducing sugars obtained from hydrolyzed lignocellulosic materials are pentoses, composed primarily of D-xylose [14]. Yeasts that have the ability to convert xylose to ethanol have been reported, and one of the earliest identified with this unique capability was Pichia stiptis [15]. For efficient conversion of all sugars to ethanol, a co-culture of OVB 11 (Sacchromyces cerevisiae) and Pichia stipitis NCIM 348 is used to co-ferment hexoses and pentoses to ethanol [14].

The average yield of wheat straw is 589.670 to $635.029 \mathrm{~g} / \mathrm{g}$ of wheat grain [16]. Wheat straw con- 
tains 35-45\% cellulose, 20-30\% hemicellulose, and 8-15\% lignin, and can also serve as a low-cost attractive feedstock for fuel alcohol production [17]. Several studies are available on the production of ethanol from wheat straw hydrolysates [18-22]. In this work, wheat straw was treated with different concentrations of perchloric acid in two-stage hydrolysis to fermentable sugars. In addition, vacuum evaporation and overliming of the hydrolysate were optimized. The fermentability of the hydrolysate was evaluated using a monoculture of baker's yeast and a co-culture of baker's yeast and P. stipitis. The optimum yields were obtained from variations of acid concentration, temperature and time. The ethanol that was produced was $11.42 \mathrm{~g} / \mathrm{l}$ in $42 \mathrm{~h}$ of incubation, with a yield of $0.475 \mathrm{~g} / \mathrm{g}$, productivity of $0.272 \mathrm{~g} / \mathrm{l} \cdot \mathrm{h}$, and fermentation efficiency of $92.955 \%$. Perchloric acid was used because of its double function as an oxidising agent and a hydrolysing agent, and it can be recyclyed from its $\mathrm{KClO}_{4}$ salt.

\section{Materials and methods}

\subsection{Wheat straw and reagents}

Sun-dried wheat straw, cultivated in June 2011, was obtained from the local harvest in Erbil, KurdistanIraq. It was further air-dried in an oven at $70^{\circ} \mathrm{C}$ for $12 \mathrm{~h}$ before it was milled in a hammer mill, and particles smaller than $0.12 \mathrm{~mm}$ were collected for further use in the experiments. The following reagents were obtained from Sigma-Aldrich: Perchloric acid $(70 \% \mathrm{w} / \mathrm{w})$, potassium hydroxide pellets, glucose, arabinose, xylose, ethanol, lime and charcoal.

\subsection{Microorganisms and Culture Media}

Hexose yeast; Dry baker's yeast (Saccharomyces cerevisiae), widely used in the bakery and brewery industries (Mauri-Pan, Instant yeast, AB Mauri Malaysia Sdn. Bhd.), was used for ethanol fermentation of glucose. The yeast $(10 \mathrm{~g} / \mathrm{l})$ was inoculated in YM broth ( $\mathrm{pH}$ 6.0), which consisted of glucose (10 g/l), peptone $(5 \mathrm{~g} / \mathrm{l})$, yeast extract $(3 \mathrm{~g} / \mathrm{l})$, malt extract $(3 \mathrm{~g} / \mathrm{l})$ and distilled water (up to 1l). This culture was incubated at $30 \mathrm{C}$ for $48 \mathrm{~h}$.

Pentose yeast; Pichia stipitis (CBS 5773), was purchased from the CBS culture collection center, Netherlands, and was used for ethanol fermentation of xylose. It was maintained on a GPYA (ATCC 144) agar plate (glucose $(40 \mathrm{~g} / \mathrm{l})$, yeast extract $(5 \mathrm{~g} / \mathrm{l})$, peptone $(5 \mathrm{~g} / \mathrm{l})$, agar $(15 \mathrm{~g} / \mathrm{l}))$ medium. It was grown in GPYA medium at $30 \mathrm{C}, 100 \mathrm{rpm}$ for $48 \mathrm{~h}$, but this growing process was done after xylose $(40 \mathrm{~g} / \mathrm{l})$ got subtituted for glucose in the medium. The preculture yeast cells were collected by centrifugation at
$6000 \mathrm{~g}$ for $10 \mathrm{~min}$. The cells were washed twice with distilled water prior to inoculation.

\subsection{Pretreatment}

\subsubsection{Acid hydrolysis}

The powdered wheat straw (10 g) was treated with perchloric acid $(17.5 \%)$ with a solid-to-liquid ratio of 1 : 4 at $100 \mathrm{C}$ for $20 \mathrm{~min}$. The mixture was cooled in an ice bath and filtered. The residual wheat straw from the filtration was kept for the second stage of hydrolysis. The filtrate was neutralised with $\mathrm{KOH}$ $(10 \mathrm{M}), \mathrm{KClO}_{4}$ was precipitated, and the solution was filtered. The residual wheat straw was hydrolysed with $\mathrm{HClO}_{4}(35 \%)$ at $100 \mathrm{C}$ for $40 \mathrm{~min}$. The filtrate from this second stage was treated as above. The sugars and the by-products were measured by HPLC.

\subsubsection{Concentrating the sugars}

The combined filtrates from above $(550 \mathrm{ml})$ were concentrated by vacuum distillation (Buchi Rotavap R215) at $80^{\circ} \mathrm{C}$. Sugars, phenolics and furans were measured by HPLC.

\subsubsection{Detoxification}

The concentrated filtrate was treated with calcium oxide with stirring, until $\mathrm{pH} 10$. This mixture was incubated for half an hour, followed by centrifugation (3000 g, $20 \mathrm{~min})$ and filtration. Later, the $\mathrm{pH}$ of the hydrolysate was brought down to $\mathrm{pH} 6$ by $\mathrm{HClO}_{4}$ (10M) [23]. Activated charcoal (3.5 g) was added to the hydrolysates and stirred for $1 \mathrm{~h}$. The mixture was centrifuged and filtered. The sugars and the byproducts were measured by HPLC.

\subsection{Fermentation}

Monoculture (S. cerevisiae); The detoxified hydrolysates $(100 \mathrm{ml})$ were taken along with supplementation of $0.1 \%(\mathrm{w} / \mathrm{v})$ yeast extract, peptone, $\mathrm{NH}_{4} \mathrm{Cl}, \mathrm{KH}_{2} \mathrm{PO}_{4}$ and $0.05 \%$ of $\mathrm{MgSO}_{4} \cdot 7 \mathrm{H}_{2} \mathrm{O}$, $\mathrm{MnSO}_{4}, \mathrm{CaCl}_{2} \cdot 2 \mathrm{H}_{2} \mathrm{O}, \mathrm{FeCl}_{3} \cdot 2 \mathrm{H}_{2} \mathrm{O}$ and $\mathrm{ZnSO}_{4} \cdot 7 \mathrm{H}_{2} \mathrm{O}$ in a $250 \mathrm{ml}$ conical flask, adjusting the $\mathrm{pH}$ to 5.5 , and autoclaved at $115^{\circ} \mathrm{C}$ for $15 \mathrm{~min}$ [23]. After the medium had been cooled to room temperature it was transferred to a $500 \mathrm{ml}$ jar (Laboratory Fermentor, B. E. MARUBISHI (THAILAND CO., LTD) under sterile conditions. Then the baker's yeast starter culture $(10 \mathrm{ml})$ was inoculated, and incubated anaerobically at $30^{\circ} \mathrm{C}, 200 \mathrm{rpm}$ for $72 \mathrm{~h}$. Samples from the medium were withdrawn periodically at various intervals from the replicated fermenter jars and centrifuged at $600 \mathrm{~g}$ for $10 \mathrm{~min}$ at $10^{\circ} \mathrm{C}$ and analyzed for ethanol. 
The fermentation efficiency was calculated using the following formula [23].

$$
F E \%=\frac{\text { Practical yield }}{\text { Theoretical yield }} \times 100 \text {, }
$$

where the practical yield is the ethanol that is produced, and the theoretical yield is 0.511 per gram of sugar consumed.

Co-culture ( $S$. cerevisiae and $P$. stipitis); The detoxified hydrolysate $(100 \mathrm{ml})$ was taken along with supplementation of $0.1 \%(\mathrm{w} / \mathrm{v})$ yeast extract, peptone, $\mathrm{NH}_{4} \mathrm{Cl}, \mathrm{KH}_{2} \mathrm{PO}_{4}$ and $0.05 \%$ of $\mathrm{MgSO}_{4} \cdot 7 \mathrm{H}_{2} \mathrm{O}$, $\mathrm{MnSO}_{4}, \mathrm{CaCl}_{2} \cdot 2 \mathrm{H}_{2} \mathrm{O}, \mathrm{FeCl}_{3} \cdot 2 \mathrm{H}_{2} \mathrm{O}$ and $\mathrm{ZnSO}_{4} \cdot 7 \mathrm{H}_{2} \mathrm{O}$ in a $250 \mathrm{ml}$ conical flask, adjusting $\mathrm{pH}$ to 5.5 , and autoclaved at $115^{\circ} \mathrm{C}$ for $15 \mathrm{~min}$ [21]. After the medium had been cooled to room temperature it was transferred to a $500 \mathrm{ml}$ jar (Laboratory Fermentor, B. E. MARUBISHI (THAILAND CO., LTD) under sterile conditions. After it had been transferred, the baker's yeast starter culture $(10 \mathrm{ml})$ was inoculated and incubated anaerobically at $30{ }^{\circ} \mathrm{C}, 200 \mathrm{rpm}$ for 24 h. Then, $P$. stipitis inoculum was added at a rate of $(10 \mathrm{~g} / \mathrm{l})$ and fermentation was allowed to continue at $30^{\circ} \mathrm{C}, 300 \mathrm{rpm}$ for $72 \mathrm{~h}$ at an aeration rate of $5 \mathrm{ml} / \mathrm{min}$. Samples from the medium were withdrawn periodically at various intervals from the replicated fermenter jars, centrifuged at $600 \mathrm{~g}$ for $10 \mathrm{~min}$ at $10^{\circ} \mathrm{C}$ and analyzed for ethanol by HPLC.

\subsection{Analytical methods}

Sugars, furfural, HMF, ethyl vanillin, syringaldehyde, acetic acid and ethanol were analysed using the Waters HPLC system with a refractive index as a detector (Waters 600E Multisolvent Delivery System, Waters 717plus Autosampler, Waters TCM column heater- item 2989 HPLC,Waters 2414 Refractive Index Detector) equipped with a Rezex column (ROROrganic Acid 00F-0138-K0, $8 \%$ H, $150 \times 7.8 \mathrm{~mm})$ and a Rezex micro-guard cartridige column (03B-0138$\mathrm{K} 0,50 \times 7.8 \mathrm{~mm})$. The eluent was $\mathrm{H}_{2} \mathrm{SO}_{4}(5 \mathrm{mM})$ at a flow rate of $0.6 \mathrm{ml} / \mathrm{min}$, and the injection volume was $10 \mu \mathrm{l}$.

\section{Results and discusion}

\subsection{Acid hydrolysis}

Perchloric acid was used because of its double function as an oxidising agent and as a hydrolysing agent. In addition to the acid hydrolyzing effect of $\mathrm{HClO}_{4}$, its oxidizing function helps in delignification and requires less time and energy than other acids pretreatments that are used [24]. In addition, neutralisation of the access $\mathrm{HClO}_{4}$ with $\mathrm{KOH}$ leads to precepitation of the insoluble $\mathrm{KClO}_{4}$, and this can be recycled to $\mathrm{HClO}_{4}$.

First stage of acid hydrolysis; The effects of temperature and time on the acid hydrolysis of wheat straw were studied. In this study, the ratio of powdered wheat straw to the volume of perchloric acid was $1: 4$, and the concentration of perchloric acid was $17.5 \%$. The effects of four different temperatures $\left(50,70,90,100{ }^{\circ} \mathrm{C}\right)$ on the hydrolysis of wheat straw were investigated. The effects of different heating times from $10 \mathrm{~min}$ to $60 \mathrm{~min}$ were also investigated at each of the above temperatures. Reducing sugars from the hydrolysis increased as the temperature and the heating time increased, as shown in Figures 1 and 2 . However, at $100{ }^{\circ} \mathrm{C}$, the concentration of arabinose decreased slightly after $20 \mathrm{~min}$ of hydrolysis, and the xylose concentration approximately stabilized. This indicated that the hemicellulose hydrolysis of wheat straw was almost complete when it was hydrolysed at $100^{\circ} \mathrm{C}$ for $20 \mathrm{~min}$. The concentrations of by-products such as furfural, HMF, ethyl vanillin, syringaldehyde and acetic acid increased as the temperature and time increased, as shown in Figures 2 and 3 . This indicates why no degradation products were observed at $50{ }^{\circ} \mathrm{C}$. Based on the results, the optimum conditions for the first stage were when hydrolysis was conducted at $100{ }^{\circ} \mathrm{C}$ for $20 \mathrm{~min}$.

Table 1: Effects of $\mathrm{HClO}_{4}$ concentrations on hydrolysis at $100{ }^{\circ} \mathrm{C}$ and for $60 \mathrm{~min}$

\begin{tabular}{|c|c|c|c|c|c|c|c|c|}
\hline $\begin{array}{c}\mathrm{HClO}_{4} \\
\%\end{array}$ & $\begin{array}{c}\text { Glucose } \\
\mathrm{g} / \mathrm{l}\end{array}$ & $\begin{array}{c}\text { Xylose } \\
\mathrm{g} / \mathrm{l}\end{array}$ & $\begin{array}{c}\text { Arabinose } \\
\mathrm{g} / \mathrm{l}\end{array}$ & $\begin{array}{c}\text { acetic acid } \\
\mathrm{g} / \mathrm{l}\end{array}$ & $\begin{array}{c}\mathrm{HMF} \\
\mathrm{g} / \mathrm{l}\end{array}$ & $\begin{array}{c}\text { Furfural } \\
\mathrm{g} / \mathrm{l}\end{array}$ & $\begin{array}{c}\text { Ethyl vanillin } \\
\mathrm{g} / \mathrm{l}\end{array}$ & $\begin{array}{c}\text { Syringaldehyde } \\
\mathrm{g} / \mathrm{l}\end{array}$ \\
\hline 17.5 & 4.226 & 4.926 & 0.958 & 0.749 & 0.345 & 0.195 & 0.26 & 0.21 \\
\hline 20 & 5.097 & 4.906 & 0.946 & 1.099 & 0.364 & 0.308 & 0.29 & 0.24 \\
\hline 25 & 6.123 & 4.876 & 0.923 & 1.783 & 0.407 & 0.396 & 0.29 & 0.28 \\
\hline 30 & 6.502 & 4.812 & 0.902 & 2.117 & 0.446 & 0.442 & 0.28 & 0.30 \\
\hline 35 & 6.765 & 4.656 & 0.889 & 2.378 & 0.479 & 0.422 & 0.27 & 0.29 \\
\hline 40 & 6.796 & 4.520 & 0.867 & 2.524 & 0.490 & 0.382 & 0.25 & 0.27 \\
\hline
\end{tabular}




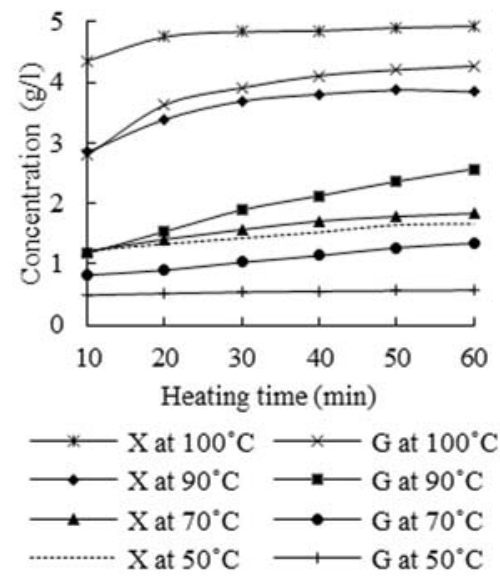

Figure 1: Effects of the temperatures and the heating times on hydrolysis (the first stage), where $\mathrm{X}$ is xylose and $\mathrm{G}$ is glucose
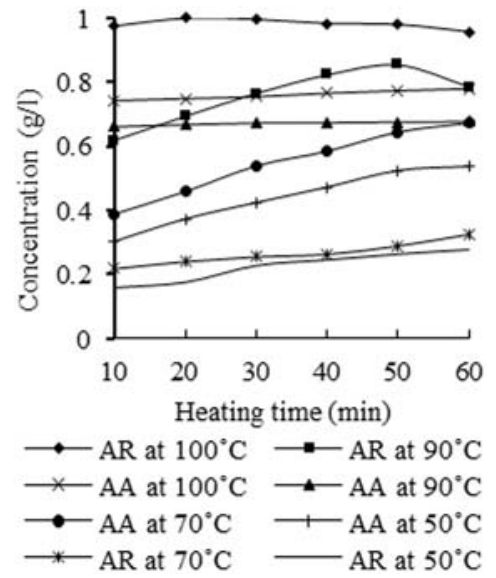

Figure 2: Effects of the temperatures and the heating times on hydrolysis (the first stage), where AR is arabinose and AA is acetic

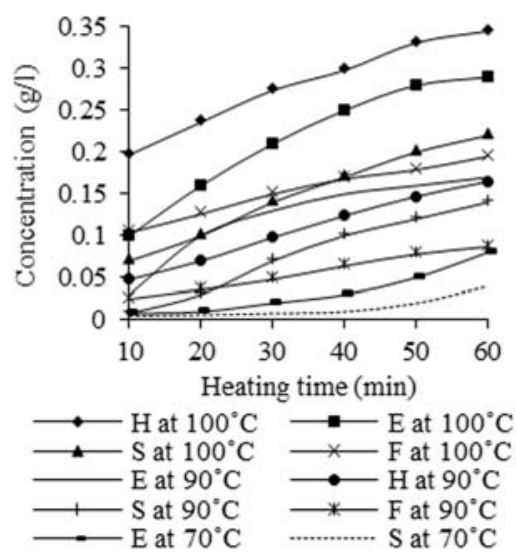

Figure 3: Effects of the temperatures and the heating times on hydrolysis (the first stage), where $\mathrm{H}$ is $\mathrm{HMF}, \mathrm{S}$ is syringaldehyde, $\mathrm{E}$ is ethyl vanilin and $\mathrm{F}$ is furfural

Table 2: Effects of heating time on the hydrolysis of wheat straw residual using $35 \% \mathrm{HClO}_{4}$ at $100{ }^{\circ} \mathrm{C}$

\begin{tabular}{|c|c|c|c|c|c|c|c|c|}
\hline $\begin{array}{c}\text { Time } \\
(\mathrm{min})\end{array}$ & $\begin{array}{c}\text { Glucose } \\
\mathrm{g} / \mathrm{l}\end{array}$ & $\begin{array}{c}\text { Xylose } \\
\mathrm{g} / \mathrm{l}\end{array}$ & $\begin{array}{c}\text { Arabinose } \\
\mathrm{g} / \mathrm{l}\end{array}$ & $\begin{array}{c}\text { Acetic acid } \\
\mathrm{g} / \mathrm{l}\end{array}$ & $\begin{array}{c}\text { Ethyl vanillin } \\
\mathrm{g} / \mathrm{l}\end{array}$ & $\begin{array}{c}\text { Syringaldehyde } \\
\mathrm{g} / \mathrm{l}\end{array}$ & $\begin{array}{c}\text { HMF } \\
\mathrm{g} / \mathrm{l}\end{array}$ & $\begin{array}{c}\text { Furfural } \\
\mathrm{g} / \mathrm{l}\end{array}$ \\
\hline 10 & 1.586 & 0.012 & 0 & 0.030 & 0.10 & 0.00 & 0 & 0 \\
\hline 20 & 2.631 & 0.087 & 0.000 & 0.057 & 0.27 & 0.02 & 0 & 0 \\
\hline 30 & 3.108 & 0.188 & 0.002 & 0.084 & 0.63 & 0.05 & 0 & 0 \\
\hline 40 & 3.325 & 0.238 & 0.003 & 0.0921 & 0.84 & 0.08 & 0 & 0 \\
\hline 50 & 3.419 & 0.270 & 0.003 & 0.134 & 1.02 & 0.12 & 0 & 0 \\
\hline 60 & 3.414 & 0.266 & 0.004 & 0.168 & 1.10 & 0.16 & 0 & 0 \\
\hline
\end{tabular}

The effects of perchloric acid concentration on the hydrolysis were investigated. The perchloric acid concentration ranged from $17.5 \%$ to $40 \%(\mathrm{w} / \mathrm{w})$. The glucose concentration from hydrolysis increased as the perchloric concentration increased, until a level of $35 \%$ was reached, after which it stabilized. Inversely, however, the xylose and arabinose concentration decreased, as shown in Table 1. These results show that hemicellulose hydrolysis of wheat straw was approximately complete when it was hydrolyzed by $17.5 \%$ perchloric acid at $100{ }^{\circ} \mathrm{C}$ for $60 \mathrm{~min}$, but the cellulose of the wheat straw still remained and continued to hydrolysis. However, the concentration of furfural, ethyl vanillin and syringaldehyde increased when the concentration of perchloric acid began to increase, but later it decreased. This is because furfural was oxidized to formic acid, ethyl vanillin was oxidized to isovanillic acid and syringaldehyde was oxidized to syringic acid by $\mathrm{HClO}_{4}$ [7]. The concentration of $\mathrm{HMF}$ continuously increased as the concentration of the acid increased, perhaps because the conversion rate of furfural is about four times faster than that of HMF [25]. Based on the results, the optimum concentration of perchloric acid for hydrolysis of cellulose was when $35 \% \mathrm{HClO}_{4}$ was used. This is guaranteed to produce a high yield of glucose. In order to prevent degradation of xylose and arabinose and to minimize the amount of by-products, it was decided to separate the hydrolysis of hemicellulose and cellulose into two separate stages.

Second stage of acid hydrolysis; The effects of various heating times from $10 \mathrm{~min}$ to $60 \mathrm{~min}$ on the hydrolysis of the wheat straw residual from the first stage filtration were investigated. In this study, $40 \mathrm{ml}$ of $35 \% \mathrm{HClO}_{4}$ and the wheat straw residue were added to the flask of the hydrolysis set, and hydrolysis was performed at $100{ }^{\circ} \mathrm{C}$. The glucose concentration from the hydrolysis increased significantly as the time of heating increased, until $50 \mathrm{~min}$, after which it declined slightly, as shown in Table 2. By contrast, only very small amounts of xylose, arabinose 


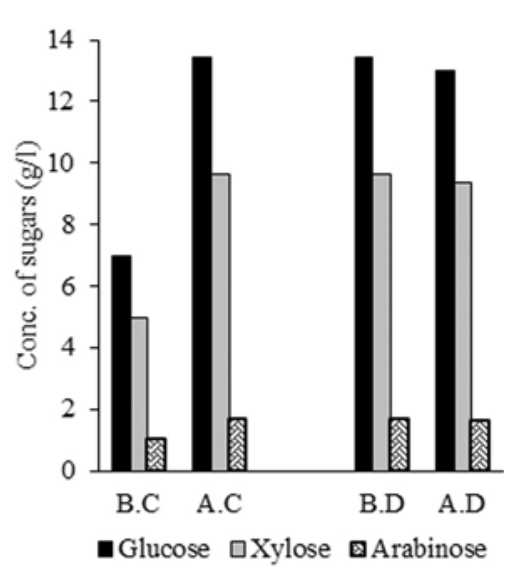

Figure 4: Effects of the hydrolysate concentrating and detoxification on the amount of sugars, where B.C. if before concentrating A.C. is after concentrating, B.D. is before detoxification and A.D. is after detoxification

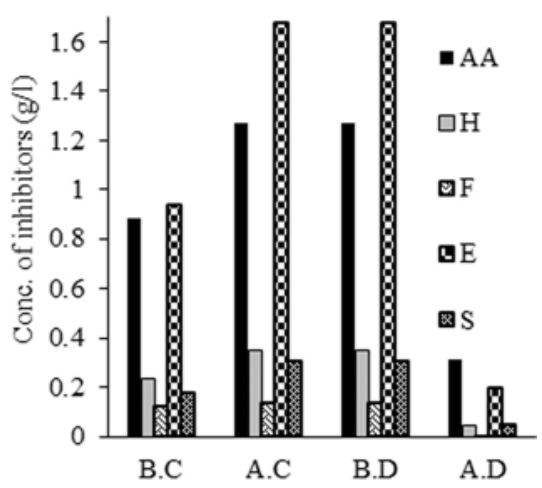

Figure 5: Effects of the hydrolysate concentrating and detoxification on the amount of inhibitors, where B.C. is before concentrating, A.C. is after concentrating, B.D. is before detoxification, A.D. is after detoxification, $\mathrm{AA}$ is acetic acid, $\mathrm{H}$ is HMF, F is furfural, $\mathrm{E}$ is ethyl vanilin and $\mathrm{S}$ is Syringaldehyde

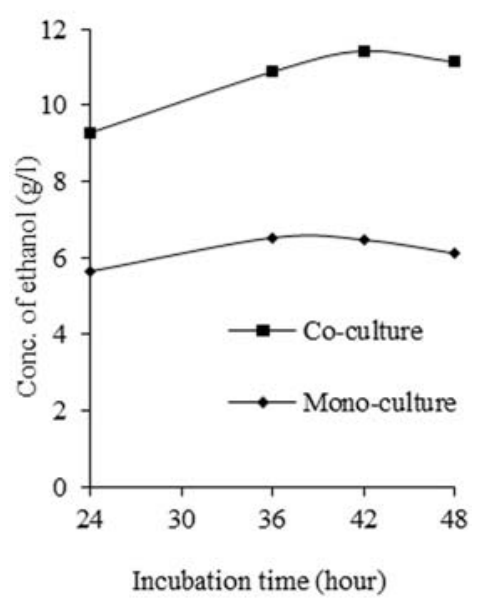

Figure 6: Effect of incubation time on the ethanol production using mono-culture (Baker's yeast) an co-culture Baker's yeast and P. stipites and acetic acid were produced, and when the heating time increased their concentration slightly increased. This is further evidence that the hemicellulose hydrolysis of wheat straw was approximately complete in the first stage of hydrolysis, but the cellulose of the wheat straw still remained and continued to hydrolyse. Therefore, as shown in Table 2, furfural and HMF were not detected. The concentration of ethyl vanillin and syringaldehyde increased with increased heating time, which may be due to degradation of lignin from the residual, as shown in Table 2. Based on the results, 50 min was selected as the optimum heating time for the second stage of hydrolysis.

\subsection{Concentrating the sugars}

The sugars were concentrated by about twofold from their initial concentrations, as shown in Figure 4. The furfural, HMF, ethyl vanillin, syringaldehyde and acetic acid contents were $0.141,0.3541 .68,0.31$, $1.27 \mathrm{~g} / \mathrm{l}$, respectively, from initial concentrations of $0.126,0.236,0.94,0.25,0.88 \mathrm{~g} / \mathrm{l}$, respectively, as shown in Figure 5. The by-products were concentrated at different rates. This may be due to degradation, e.g. furfural to acetic acid and formic acid [26].

\subsection{Detoxification}

Partial neutralization, over-liming and activated charcoal treaments were used to minimize the effect of the microbial inhibitors (by-products) caused by acid hydrolysis, and to improve the formation of ethanol during the fermentation process. This process led to a reduction by $87.2 \%, 86.2 \%, 75 \%$, $84.9 \%$ and $84.4 \%$ in furfural, HMF, acetic acid, ethyl vanillin and syringaldehyde, respectively, as shown in Figure 5. Lower amounts of glucose $(3.03 \%)$, xylose $(2.95 \%)$ and arabinose $(2.79 \%)$ were absorbed, as shown in Figure 4.

\subsection{Fermentataion}

Monoculture ethanol fermentation using baker's yeast (Saccharomyces cere visiae): The fermentability of the concentrated and detoxified hydrolysate was evaluated using the baker's yeast starter culture. The highest concentration of ethanol was $6.516 \mathrm{~g} / \mathrm{l}$ after $36 \mathrm{~h}$ of incubation, as shown in Figure 6. The resulting yield of ethanol was eqiuvalent to $0.271 \mathrm{~g} / \mathrm{g}$ with volumetric productivity of $0.181 \mathrm{~g} / \mathrm{l} \cdot \mathrm{h}$ and fermentation efficiency of $53 \%$, based on the total fermentable sugars $24.044 \mathrm{~g} / \mathrm{l}$ of the hydrolysate. The ethanol efficiency declined after $36 \mathrm{~h}$ of incubation. This may be because most of the xylose remained unfermented by the baker's yeast, as the hydrolysate contain pentoses and hexoses.

Co-culture ethanol fermentation using baker's yeast and $P$. stipitis; The fermentability of the concentrated and detoxifided hydrolysate of wheat straw was evaluated using the co-culture of baker's yeast and P. stipitis. The highest concentration of ethanol was $11.421 \mathrm{~g} / \mathrm{l}$ after $42 \mathrm{~h}$ as the optimum incubation period for maximum fermentation efficiency of 
92.955\%, as shown in Figure 6. The resulting yield of ethanol was eqiuvalent to $0.475 \mathrm{~g} / \mathrm{g}$, with volumetric productivity of $0.272 \mathrm{~g} / \mathrm{l} \cdot \mathrm{h}$, based on the total fermentable sugars $(24.044 \mathrm{~g} / \mathrm{l})$ of the hydrolysate. However, the ethanol productivity declined after $42 \mathrm{~h}$ of incubation. The higher ethanol yield is attributed to the fermentation of both hexoses and pentoses in the hydrolysate.

\section{Conclusion}

Bioethanol was produced from wheat straw using two different concentrations of perchloric acid hydrolysis in two separate stages. Perchloric acid was used because of its double function as an oxidizing agent and as a hydrolyzing agent, and it can also be recycled from its $\mathrm{KClO}_{4}$ salt. Two-stage hydrolosis was preferred to one-stage hydrolysis because there is less sugar degradation from the hydrolyzed materials in the first stage. Fewer fermentation inhibitors formed, and less heating time was required during two-stage hydrolysis.

A higher yield of ethanol was obtained by concentrating the sugars that were produced and detoxifying the inhibitors in the hydrolysate. The use of a co-culture of $S$. cerevisiae and $P$. stipitis for fermenting the concentrated and detoxified hydrolysate led to bioconversion of both hexoses and pentoses with higher ethanol yields than for ethanol fermentation by a monoculture of $S$. cerevisiae.

\section{Acknowledgement}

This study was carried out between the University of Salahaddin/Erbil — Kurdistan region-Iraq and the University of Malaya - Malaysia as research collaboration, a Sabbatical Leave program of the Ministry of Higher Education and Scientific Research, Kurdistan region-Iraq. We want to thank Associate Prof. Dr. Koshy Philip for letting us use his lab., and we also thank Mr. Kelvin Swee Chuan Wei, and Miss Ainnul Azizan for assisting us with our work.

\section{References}

[1] Millati, R., Niklasson, C., Taherzadeh, M. J.: Effect of $\mathrm{pH}$, time and temperature of overliming on detoxification of dilute-acid hydrolysates for fermentation by Saccharomyces cerevisiae, Process Biochem. 38, 4, 2002, $515-522$.

[2] Palmqvist, E., Hahn-Hägerdal, B.: Fermentation of lignocellulosic hydrolysates. II: Inhibitors and mechanisms of inhibition, Bioresource Technol. 74, 2000, 25-33.
[3] Carvalheiro, F., Duarte, L., Gírio, F. M.: Hemicellulose biorefineries: a review on biomass pretreatments, Journal of Scientific \& Industrial Research, 67, 2008, 849-864.

[4] Gonzalez, G., Lopez-Santin, J., Caminal, G., Sola, C.: Dilute Acid Hydrolysis of Wheat Straw. Hemicellulose at Moderate Temperature: A Simplified Kinetic Model, Biotechnology and Bioengineering, 28, 1986, 288-293.

[5] Yah, C. S., Iyuke, S. E., Unuabonah, E. I., Pillay, O., Vishanta, C., Tessa, S. M.: Temperature optimization for bioethanol production from corn cobs using mixed yeast strains, OnLine J. Bio. Sci., 10, 2010, 103-108.

[6] Li, C., Knierim, B., Manisseri, C., Arora, R., Scheller, H., et al.: Comparison of dilute acid and ionic liquid pretreatment of switchgrass: Biomass recalcitrance, delignification and enzymatic saccharification, Bioresource Technol., 101, 2010, 4900-4906.

[7] Taherzadeh, M. J., Karimi, K.: Acid-based hydrolysis processes for ethanol from lignocellulosic materials: A review, BioResources, 2, 3, 2007, 472-499.

[8] Jones, J., Semrau, K.: Wood hydrolysis for ethanol production - Previous experience and the economics of selected processes, Biomass, 5, 1984, 109-135.

[9] Bobleter, O., Pape, G.: Method to degrade wood, bark and other plant materials, Aust Pat 263661, 1968.

[10] Schultz, T. P., Templeton, M. C., Biermann, C. J., Mcginnis, G. D.: Steam explosion of mixed hardwood chips, rice hulls, corn stalks, and sugar cane bagasse, J. Agri. Food Chem., 32, 1984, 1166-1 172.

[11] Mcginnis, G. D., Wilson, W. W., Mullen, C. E.: Biomass pretreatment with water and highpressure oxygen - the wet oxidation process, Ind. Eng. Chem. Prod. Res. Develop., 22, 1983, 352-357.

[12] Bjerre, A. B., Olesen, A. B., Fernqvist, T., Ploger, A., Schmidt, A. S.: Pretreatment of wheat straw using combined wet oxidation and alkaline hydrolysis resulting in convertible cellulose and hemicellulose, Biotechnol Bioeng, 49, 1996, 568-577.

[13] Holtzapple, M. T., Jun, J. H., Ashok, G., Patibandla, S. L., Dale, B. E.: The Ammonia Freeze Explosion (AFEX) Process - A practical lignocellulose pretreatment, Appl. Biochem. Biotechnol., 28, 9, 1991, 59-74. 
[14] Slininger, P., Bothast, R., VanCauwenberge, J., Kurtzman, C. P.: Conversion of D-xylose to ethanol by the yeast Pachysolen tannophilus. Biotechnol. Bioeng., 24, 1982, 371-384.

[15] Du Preez, J., Prior, B.: A quantitative screening of some xylose fermenting yeast isolates, Biotechnol. Lett. 7, 1985, 241-246.

[16] Montane, D., Farriol, X., Salvado, J., Jollez, P., Chornet, E.: Application of stream explosion to the fractionation and rapid vapourphase alkaline pulping of wheat straw. Biomass Bioenergy, 14, 1998, 261-276.

[17] Gould, J.: Alkaline peroxide delignification of agricultural residues to enhance enzymatic saccharification, Biotechnol. Bioeng., 24, 1984, 46-52.

[18] Ahring, B., Jensen, K., Nielsen, P., Bijerre, A., Schmidt, A. S.: Pretreatment of wheat straw and conversion of xylose and xylan to ethanol by thermophilic anaerobic bacteria. Bioresour. Technol., 58, 1996, 107-113.

[19] Ahring, B., Licht, D., Schmidt, A., Sommer, P., Thomsen, A.: Production of ethanol from wet oxidized wheat straw by Thermoanaerobacter mathranii. Bioresour. Technol., 68, 1999, 3-9.

[20] Klinke, H., Olsson, L., Thomsen, A., Ahring, B.: Potential inhibitors from wet oxidation of wheat straw and their effect on ethanol production by Saccharomyces cerevisiae: wet oxidation and fermentation by yeast. Biotechnol. Bioeng., 81, 2003, 738-747.

[21] Nigam, J.: Ethanol production from wheat straw hemicellulose hydrolyzate by Pichia stipitis. J. Biotechnol., 87, 2001, 17-27.

[22] Delgenes, J., Moletta, R., Navarro, J.: Acid hydrolysis of wheat straw and process considerations for ethanol fermentation by Pichia stipitis Y7124. Proc. Biochem., 25, 1990, 132-135.

[23] Yadav, K., Naseeruddin, S., Sai Prashanthi, G., Sateesh, L., Rao, L.: Bioethanol fermentation of concentrated rice straw hydrolysate using coculture of Saccharomyces cerevisiae and Pichia stipites, Bioresource Technology, 102, 11, 2011, 6473-6478.

[24] Carlos Martin, Marcelo Marcet, Anne Belindo Thomsen: Comparison between wet oxidation and steam explosion as pretreatment methods for enzymatic hydrolysis of sugarcane bagasse, BioResources, 3, 3, 2008, 670-683.

[25] Harris, J., Baker, A., Zerbe, J.: Two-stage, dilute sulfuric acid hydrolysis of hardwood for ethanol production, Energy Biomass Wastes, 8, 1984, 1 151-1 170 .

[26] Dehkhoda, A., Brandberg, T., Taherzadeh, Mohammad: Comparison of vacuum and high pressure evaporated wood hydrolysate for ethanol production by repeated Fed batch using flocculating Saccharomyces cerevisiae, Bioresources, 4, 1, 2008, 309-320. 